\title{
La referencia electrónica en artículos científicos
}

\author{
Hernán Sagua Fla.
}

\section{Analysis of electronic references in a volume of Revista Médica de Chile}

Background: Publications in electronic format using Web sites facilitates and extends the access to information from any place in the world. Nevertheless, the use of electronic references still lacks the rigor with which the printed reference is handled. Aim: To analyze the citation of electronic references in Revista Médica de Chile. Material and methods: Twelve issues of volume 132 were analyzed, quantifying the number of electronic references. Their accuracy was assessed considering the elements available in the Web site and access date. Results: Seventy six electronic references were detected. Of these, 28 (37\%) incorporated available in, 76 (100\%) indicated the Web site and 38 (50\%) indicated the access date. Conclusions: Electronic references are still scanty and incomplete in Revista Médica de Chile (Rev Méd Chile 2007: 135; 939-41).

(Key words: Bibliography; Internet; Publications)

Recibido el 19 de diciembre, 2005. Aceptado el 28 de noviembre, 2006.
1Facultad Ciencias de la Salud, Universidad de Antofagasta. Chile.
aTecnólogo Médico

$E^{1}$ 24 de octubre de 1995, el Federal Networking Council (FNC) de los Estados Unidos de Norteamérica aprobó la resolución donde se definió el término Internet. A partir de ese momento comenzó la era del documento electrónico accesible desde cualquier parte del mun$\mathrm{do}^{1,2}$.

El sistema inicialmente utilizó los servicios Gopher, FTP, Telnet entre otros y después por medio del servicio WWW. Los sitios Web, por sus características gráficas y flexibilidad, constituyen la herramienta básica de Internet ${ }^{3}$.

La oportunidad de diseminar, promover y divulgar información en el mundo, junto a la disponibilidad de consulta en cualquier momento

Correspondencia a: Hernán Sagua Franco. Casilla 170. Antofagasta, Chile. Fax: 637802. E mail: hsagua@uantof.cl o lugar, desarrollaron aceleradamente el fenómeno de la publicación en formato electrónico ${ }^{2,3}$.

En este contexto surgió la necesidad de describir bibliográficamente estas fuentes electrónicas, para que los autores puedan documentar o citar sus investigaciones. Con este propósito se han elaborado varias guías, manuales y normas, pero hasta hoy en día ninguna se considera oficial ${ }^{3-5}$. El problema consiste en incorporar los elementos descriptivos necesarios para identificar y recuperar los datos disponibles en red, sin variar el modelo establecido para los documentos tradicionales.

Un artículo científico incluye en la lista de referencias, documentos consultados en diferentes tipos de soporte: revistas científicas, libros, capítulos de libros, Internet, comunicaciones en congresos, etc., por lo cual es válido exigir que aparezcan con características comunes y coherentes. 
Este trabajo tiene como propósito orientar a los autores acerca del estilo y forma en que deben citar las referencias electrónicas, para que la literatura citada se pueda recuperar y contribuir a la promoción de los resultados científicos registrados en los sitios Web. Para este análisis se ha seleccionado a la Revista Médica de Chile, la cual está en importantes bases de datos y es editada en versión impresa y electrónica ${ }^{4}$.

Con ese propósito se analizaron los 12 números del volumen 132, del año 2004, de Revista Médica de Chile. En cada trabajo se revisó el listado de referencias para contabilizar el número de referencias electrónicas y la calidad de su construcción, exigiendo a lo menos tres elementos: \$isponible en:», «Sitio Web»y «Fecha de consulta».

La Tabla 1 resume el número y calidad de construcción de las referencias electrónicas utilizadas, destacándose el bajo número de referencias electrónicas registradas (76) en el volumen 132, excepto en el número 12 de la Revista que contiene 23 referencias electrónicas, 22 de ellas en un mismo trabajo (y 20 bien construidas).

\section{Comentarios}

Los documentos en línea tienen dos características principales: su movilidad y el que son fáciles de modificar. En general, los elementos que universalmente los identifican son: 1 . Disponibilidad o acceso; 2. Sitio Web; 3. Fecha de consulta; 4. Fecha de actualización.

Aunque en las Instrucciones a los Autores la Revista Médica de Chile establece las indicaciones para el uso de las referencias electrónicas en la forma que se transcribe ${ }^{4}$ : Para artículos en formato electrónico: Citar autores, título del artículo y revista de origen tal como para su publicación en papel, indicando a continuación el sitio electrónico donde se obtuvo la cita y la fecha en que se hizo la consulta.

Ej: Rev Méd Chile 2003; 131: 473-482. Disponible en: www.Scielo.cl [Consultado el 14 de julio de 2003]», llama la atención el bajo número de referencias electrónicas utilizadas (76) y también el bajo porcentaje de autores que cumplieron dichas exigencias, ya que en los 12 números del volumen analizado sólo en $36,8 \%$ de las referen-

Tabla 1. D istribución y calidad de construcción de referencias electrónicas en los 12 números del volumen 132 de la Revista M édica de C hile, 2004

\begin{tabular}{|ccccc|}
\hline $\begin{array}{c}\text { Números } \\
\text { Editados }\end{array}$ & $\begin{array}{c}\text { No Referencias } \\
\text { electrónicas }\end{array}$ & $\begin{array}{c}\text { Calidad de construcción } \\
\text { Disponible en: }\end{array}$ & Sitio Web & Fecha de consulta \\
\hline 1 & 2 & 0 & 2 & 1 \\
2 & 1 & 1 & 1 & 0 \\
3 & 6 & 3 & 6 & 0 \\
4 & 2 & 1 & 2 & 1 \\
5 & 8 & 0 & 8 & 5 \\
6 & 3 & 0 & 3 & 1 \\
7 & 4 & 0 & 4 & 2 \\
8 & 1 & 0 & 1 & 0 \\
9 & 15 & 2 & 15 & 7 \\
10 & 11 & 1 & - & - \\
11 & 0 & - & 23 & 20 \\
12 & 23 & 20 & 76 & 38 \\
Totales & 76 & 28 & 11 & 50,0 \\
\hline
\end{tabular}


cias los autores incorporaron los términos «Disponible en» mientras que sólo en $50,0 \%$ de ellas aparece registrada la đecha de consulta»(Tabla 1).

La cita de una publicación electrónica descrita con los elementos esenciales que la identifican, facilita su consulta inmediata con sólo disponer de una computadora conectada a Internet, y la rapidez con que se recupera este tipo de información tiene valor agregado para el lector.

Se dice que el futuro es de las publicaciones en línea, y que la edición electrónica de una revista (o referencia) citada con los elementos de

\section{REFERENCIAS}

1. GibaLDi J. MLA handbook for writers of research papers. $4^{\text {th }}$ ed. New York: The Modern Language Association of America, 1995.

2. Crouse M. 2001. Citing Electronic Information in History Papers. Disponible en: http:/ www.people.mephis.edu/mcrouse/elcite.html Consulta: septiembre 2004.

3. Library \& InFormation Science: Citation Guides for Electronic Documents. Disponible en: http:/ localización y acceso correctos, amplía la posibilidad de consulta de los lectores, activa el ciclo reiterativo de la referencia y contribuye con la promoción y frecuencia de uso de sitios Web.

Finalmente se debe tener presente que el International Committee of Medical Journal Editors ha normado la construcción de siete formatos para el material electrónico que se requiere citar en las publicaciones de revistas biomédicas, incluyendo las fechas de actualización y de consulta, disponible en: y el sitio Web correspondiente, en seis de ellos, excepto los discos compactos ${ }^{5}$.

www.ifla.org/index.htm. Consulta: septiembre 2004.

4. Revista Médica de Chile. Instrucciones a los autores. Disponible en: http://www.scielo.cl/revistas/ $\mathrm{rmc}$ /einstruc.htm. Consulta: 14 diciembre 2005.

5. Uniform Requirements for Manuscripts Submitted to Biomedical Journals: Writing and Editing for Biomedical Publication. Fecha actualización: Octubre,2005. Disponible en: http:/www.nml.nih.gov/ bsd/uniform_requirements.html/. Consulta: 12 diciembre $200 \overline{5}$. 